\title{
The Effect of Director's Servant Leadership and Social Support of Colleague Teachers on Childcare Teachers' Organizational Commitment
}

\section{원장의 서번트 리더십과 동료교사의 사회적 지지가 보육교사의 조직몰입에 미치는 영향}

Ji-Hyang Choi ${ }^{1}$, Sung-On Hwang ${ }^{2}$

최지향 1 황성온 2

${ }^{1}$ Graduate Student, Early Childhood Education, Incheon National University, Korea, gadir0148@naver.com

${ }^{2}$ Professor, Early Childhood Education, Incheon National University, Korea, hso@inu.ac.kr

Corresponding author: Sung-On Hwang

\begin{abstract}
The purpose of this study is to determine the impact of director's servant leadership and the social support of colleague teachers on childcare teachers' organizational commitment. The survey was conducted on 240 teachers working in childcare centers in G province and I city who were chosen through convenience sampling. The collected data were analyzed using the program SPSS 22.0. Cronbach's $\alpha$ coefficient was estimated for the reliability of the research instruments and pearson's correlation analysis was carried out to find out the correlation between research variables. Lastly, multiple regression analysis was also performed to determine the relative influence of the director's servant leadership and the social support of colleague teachers on childcare teachers' organizational commitment. The results of this study can be summarized as follows. First, a positive correlation was found between director's servant leadership, the social support of colleague teachers, and childcare teachers' organizational commitment. Second, the relative impact of director's servant leadership and the social support of colleague teachers were also found to have the on childcare teachers' organizational commitment had meaningful explanatory power. The director's servant leadership had a relatively greater influence on organizational commitment of childcare teacher than the social support of colleague teachers. These results suggest that director's servant leadership and the social support of colleague teachers can be important factors for childcare teacher's organizational commitment. The results of this study are intended to provide basic data for improving the quality of childcare services by finding ways to improve organizational commitment of childcare center teachers.
\end{abstract}

Keywords: Director's Servant Leadership, Social Support of Colleague Teachers, Organizational Commitment, Childcare Teacher

요약: 본 연구는 원장의 서번트 리더십과 동료교사의 사회적 지지가 보육교사의 조직몰입에 미치는 상대적 영향력을 알아보는 데 그 목적이 있다. 이를 위하여 G 도, I 시에 소재한 어린이집에서 근무 중인 보육교사 240 명을 대상으로 설문조사를 실시하였다. 수집된 자료는

Received: August 27, 2021; 1st Review Result: October 13, 2021; 2nd Review Result: November 26, 2021

Accepted: December 31, 2021

*This article is a part of Ji-Hyang Choi's master's thesis submitted in 2020. 
SPSS 22.0 프로그램을 사용하여 통계처리 하였다. 측정 도구의 신뢰도 검증을 위해서 Cronbach's $\alpha$ 계수를 산출하였다. 또한 Pearson의 상관분석과 다중 회귀분석을 실시하였다. 자료 분석 결과는 다음과 같다. 첫째, 원장의 서번트 리더십과 동료교사의 사회적 지지, 보육교사의 조직몰입 간에 모두 통계적으로 유의미한 정적 상관관계가 있는 것으로 나타났다. 둘째, 원장의 서번트 리더십과 동료교사의 사회적 지지는 보육교사의 조직몰입을 예측하는 변인이며, 원장의 서번트 리더십이 동료교사의 사회적 지지보다 보육교사의 조직몰입에 미치는 영향력이 더 큰 것으로 나타났다. 이러한 결과는 원장의 서번트 리더십과 동료교사의 사회적 지지가 보육교사의 조직몰입에 대한 중요한 예측 변인임을 시사한다. 본연구결과를 통해 보육교사의 조직몰입을 증진하는 방안이 모색되어 보육서비스의 질적 향상을 위한 기초자료로 활용되길 기대해 본다.

핵심어: 원장의 서번트 리더십, 동료교사의 사회적 지지, 조직몰입, 보육교사

\section{1. 서론}

현대사회의 급격한 산업화와 도시화로 여성의 경제활동 참여율이 증가하면서 가정의 자녀 양육기능은 과거보다 약화하고 있다. 그로 인해 영유아의 보육에 대한 사회적 관심이 높아져 보육 기관의 양적 확대가 이루어졌고, 기관의 질적 관리 및 향상에 대한 논의가 중요하게 다뤄지고 있다[1].

보육교사는 보육 기관의 질적 향상과 관련하여 매우 중요한 변인이다[2]. 그 이유는 보육교사가 조직의 구성원으로서 기관에 적응하고, 일체감을 느끼며 기관의 목표 성취를 위해 구성원들과 노력하는 태도를 가질 때 기관의 질적 향상에 긍정적인 영향을 미칠 수 있기 때문이다[3][4]. 이와 관련하여 보육교사의 조직몰입을 주목해 볼 필요가 있다. 보육교사의 조직몰입이란, 보육교사가 기관에서 정한 교육목표와 가치에 대한 확고한 신념을 바탕으로 조직의 발전을 위해 노력하는 의지를 지칭한다[5]. 즉 보육교사는 기관의 목표와 가치를 수용하고, 기관의 목표 달성을 위한 자발적 의지가 생길 때 높은 직무 성과를 유발할 수 있다[6].

보육교사의 조직몰입에 관한 선행연구를 살펴보면, 보육교사의 조직 몰입도가 높은 경우 교수 역량이 높고[7], 업무 수행능력이 뛰어나 보다 양질의 보육 서비스를 제공할 수 있는 것으로 나타났다[8][9]. 반면, 조직몰입 수준이 낮은 보육교사는 기관에 대한 열정이 낮고, 영유아와 양질의 상호작용을 하지 못하며, 교육의 질 전반에 걸쳐 부정적인 영향을 미치는 것으로 밝혀졌다[10]. 이처럼 보육 기관의 목표 달성, 교사 전문성 신장, 영유아들의 발달과 적응 및 교육에 미치는 긍정적인 영향 등[11]을 고려해 보았을 때, 보육교사들의 긍정적인 조직몰입이 매우 중요한 변인임을 알 수 있다.

본 연구에서는 보육교사의 조직몰입에 영향을 미치는 변인으로 기관의 인적 환경인 ‘원장’과 ‘동료교사'에 중점을 두고 각각에 대해 살펴보고자 한다. 원장의 경우, 교육철학과 운영방식이 보육교사를 비롯하여 기관에 취원 중인 영유아에게도 영향력을 미칠 정도로 영향력이 크다고 할 수 있다[12]. 보육 기관은 다른 교육기관과 달리 가정과 학교의 특징을 동시에 내포하고 있어 세심함, 배려, 사랑, 봉사, 가족과 같은 분위기가 강조되는 곳이므로[13], 원장은 명령 또는 지시형식이 특징인 전통적, 권위적인 리더십보다는 구성원들의 자발적인 헌신과 참여를 유도하고, 주인의식과 책임감을 고취하는 서번트 리더십(Servant Leadership)과 같은 유형의 리더십을 발휘해야 한다[14]. 
서번트 리더십이란 타인을 위하는 봉사에 초점을 두고 조직구성원, 지역 공동체를 우선하여 여기며 그들의 요구를 위해 헌신하는 리더십[15]으로, 구성원을 성장과 성공의 대상으로 생각하고 각 구성원이 자기 일에서 성장할 수 있도록 코치와 지원을 강화해 주는 특징을 보인다[16][17]. 서번트 리더십에 대한 연구는 시대적 배경과 관점에 따라 변화하며 현재까지 다양한 방향에서 이루어져 왔으며[18], 배려의 리더십 혹은 섬기는 리더십, 하인의 리더십 등으로 불리기도 하였다. 서번트 리더십을 가진 사람은 구성원의 의견을 경청하며, 격려하고 보살피며, 존중하고 구성원들의 가능성을 신뢰하며, 구성원을 이해하려고 노력하고 구성원의 발전을 장려하고, 권한을 위임하며, 도덕성을 갖추고 상하 관계에 상관없이 공동체를 형성하는 특징이 있다[18][19]. 보육기관의 리더인 원장은 조직을 혼자서 이끌어가는 일방적인 리더십이 아니라, 구성원과 수평적인 관계를 형성하여 보육교사와 같이 고민하고, 개개인의 욕구와 가치를 존중하여 공동체를 형성해 나가는 서번트 리더십을 갖출 때, 기관 내 보육교사는 기관 업무에 자발적으로 참여하고, 주인의식과 책임감이 고취되어[12], 조직몰입이 더욱 향상될 수 있을 것이다.

원장의 서번트 리더십에 관한 선행연구를 살펴보면, 보육교사가 지각하는 원장의 서번트 리더십 정도가 높을수록 보육교사의 교직 헌신도 및 교사효능감이 높은 것으로 나타났다[14]. 또한 원장의 서번트 리더십이 적절히 발휘될 경우 구성원들 간에 서로를 신뢰하는 분위기가 형성되어, 보육교사의 직무만족도를 높이고[18], 보육교사의 조직몰입을 높여 구성원 간의 협동을 높이고 조직의 성과를 증진한다고 하였다[19]. 이와 같은 선행연구의 결과를 통해 원장의 서번트 리더십이 보육교사에게 긍정적인 영향을 주는 중요한 변인임을 알 수 있다.

원장의 서번트 리더십에 이어, 보육교사의 조직몰입에 영향을 미치는 교사의 인적환경 변인 중 동료교사로부터 받는 사회적 지지에 대해서 살펴보고자 한다. 사회적 지지란 가족, 친척, 직장동료 등 대인관계로부터 받을 긍정적인 자원으로 타인과의 상호작용을 통해 충족될 수 있는 기본적인 욕구를 의미하는데[20], 본 연구에서는 기관 내 동료교사로부터 받는 사회적 지지로 의미를 제한하고자 한다. 사회적 지지와 보육교사의 조직몰입에 관한 선행연구를 살펴보면, 풍부한 사회적 지지를 받는 보육교사일수록 조직에 더 깊숙이 몰입하는 것으로 나타났다[21]. 이는 사회적 지지는 환경으로부터 받게 되는 스트레스를 감소시켜주어 교사가 환경에 더욱 잘 적응할 수 있도록 돕고, 업무 만족과 심리적 만족에 긍정적인 영향을 미쳐 결과적으로 조직에 대한 만족감을 비롯하여 친밀감을 높여 보육교사의 조직몰입을 강화해 줄 수 있다고 하였다[22]. 따라서 보육교사의 기관 내 인적 환경인 동료교사의 사회적 지지가 조직몰입에 긍정적인 영향을 미치는 중요한 변인임을 알 수 있다.

위의 선행연구 결과들을 살펴본 결과 원장의 서번트 리더십, 동료교사의 사회적 지지, 보육교사의 조직몰입 간에 관련성이 있는 것을 알 수 있다. 이미 선행연구에서 세 변인과의 관계성 내지 영향력을 살펴보는 연구는 이루어졌으나 사회적 지지의 경우 동료교사를 포함하여 가족, 친척, 이웃 등 다양한 범주의 주변인들로부터의 광범위한 사회적 지지였다. 그러므로 본 연구에서는 보육교사의 기관 내 주요 인적환경인 원장과 동료교사에 중점을 두고 원장의 서번트 리더십 그리고 동료교사의 사회적 지지를 주요 변인으로 보육교사의 조직몰입에 미치는 영향력을 살펴보고자 한다. 본 연구를 통해 보육교사의 조직몰입을 높일 방안을 연구하여, 보육의 질적 향상을 위한 프로그램 개발에 필요한 기초자료를 제공하고자 한다. 
연구문제 1. 원장의 서번트 리더십, 동료교사의 사회적 지지, 보육교사의 조직몰입 간의 관계는 어떠한가?

연구문제 2. 원장의 서번트 리더십과 동료교사의 사회적 지지가 보육교사의 조직몰입에 미치는 상대적 영향력은 어떠한가?

\section{2. 연구방법}

\section{1 연구대상}

$\mathrm{G}$ 도와 I 시에 소재한 어린이집 교사 $(\mathrm{N}=240)$ 를 연구대상으로 선정하였다. 어린이집 유형의 경우에는 국공립이 $34.2 \%$ 로 가장 많았으며 민간 $29.4 \%$, 가정 $19.0 \%$, 직장 $6.7 \%$ 순으로 나타났다. 직위의 경우에는 담임교사가 $85.8 \%$ 로 대부분을 차지하였으며 주임교사 $10.4 \%$, 원감 $3.8 \%$ 이었다. 연령의 경우 40 대가 $37.1 \%$ 로 가장 많았으며 30 대가 $26.7 \%$, 20 대가 $20.4 \%, 50$ 대 이상이 $15.8 \%$ 순으로 나타났으며 최종학력의 경우 2,3 년제 대졸이 $48.3 \%$ 로 가장 많았으며 4 년제 대졸이 $31.7 \%$, 보육교사 교육원이 $16.7 \%$, 대학원 졸업이 $3.3 \%$ 순으로 나타났다. 근무경력의 경우 3 4년이 $26.7 \%$ 로 가장 많았으며, 7 9년이 $24.2 \%$, 10 년 이상이 $15 \%, 1 \sim 2$ 년이 $11.3 \%, 1$ 년 미만이 $7.5 \%$ 순으로 나타났다.

\section{2 연구도구}

\subsection{1 원장의 서번트 리더십}

원장의 서번트 리더십을 측정하기 위해 $\operatorname{Laub(1999)[23]ㅇㅣ~ㄱㅐㅂㅏㄹㅎㅏㄴ~ㅅㅓㅂㅓㄴㅌㅡ~ㄹㅣㄷㅓㅅㅣㅂ~ㅊㅡㄱㅈㅓㅇ~}$ 도구 SOLA(Assessing the Servant Organization: Development of the Servant Organizational Leadership Assessment)를 기초로 Spears(1996)[24]의 서번트 리더십의 특성을 참고하여 성복련(2010)[25]이 개발한 학교장의 서번트 리더십 설문지를 사용하였다. 본 도구는 가치존중(4문항), 성장지원(4문항), 공동체 형성(4문항), 진정성(4문항), 리더십 발휘(4문항), 리더십 공유(4문항)의 6가지 하위요인에 걸쳐 총 24 문항으로 구성되어 있다. 하위요인별 내용을 살펴보면 '가치존중'은 교사를 존중하고, 필요한 것에 봉사, 경청하고, 사람을 믿는 것을 의미한다. '성장지원'은 교사가 학습할 기회를 제공하고, 교사의 능력 개발에 지원하며, 격려로 다른 사람들을 발전시키고, 행동 양식에 모델이 되는 것을 의미하고, ‘공동체 형성'은 친밀한 인간관계를 가지고 서로 협동하여 일하며 교사들의 공동체 형성을 돕고, 개인적 차이를 높게 평가하는 것이다. '진정성'은 자진해서 기꺼이 하는 마음, 책임감, 솔직함, 신뢰감, 다른 사람으로부터 배우려는 성실성을 의미하고, ‘리더십 발휘는 목표를 명백하게 하고 리더십을 발휘하며, 솔선수범하여 미래를 구상하는 것을 말한다. '리더십 공유'란 조직에서 비전과 권한을 공유하고, 의사결정 및 지위와 특권을 공유하는 것을 의미한다. 각 문항은 Likert 5 점 척도로 평정하게 되어 있으며, 점수가 높을수록 보육교사가 지각하는 원장의 서번트 리더십이 높음을 의미한다. 연구 도구의 신뢰도계수는 Cronbach $\alpha=.97$ (가치존중 .93, 성장지원 .91, 공동체 형성 .87 , 진정성 .81 , 리더십 발휘 .91, 리더십 공유 .89)이다.

\subsection{2 동료교사의 사회적 지지}

동료교사로부터의 사회적 지지를 측정하기 위한 도구로 박지원(1985)[26]이 개발한 사회적 지지 척도를 안혜정(2013)[27]이 적합하게 수정·보완한 척도를 사용하였다. 본 
도구는 정서적 지지(6문항), 정보적 지지(6문항), 도구적 지지(6문항), 평가적 지지(6문항)의 4 가지 하위요인에 걸쳐 총 24 문항으로 구성되어 있다. 하위요인별 내용을 살펴보면, '정서적 지지'는 조직 내 구성원에게 사랑, 관심, 존중, 신뢰를 받고 있다고 느껴지는 정서적 측면의 지원을 의미한다. '정보적 지지'는 본인의 개인적 문제를 해결하는 데 이용할 수 있는 조언, 제안, 정보 등을 조직 내 구성원들이 제공해 주는 것을 의미한다. '도구적 지지'는 직접적인 도움이 필요로 할 때 구성원들이 물건 혹은 현금을 제공하거나 업무를 대신해주는 등의 지원을 의미한다. 마지막으로 '평가적 지지'는 자신의 행위에 대해 구성원들이 칭찬, 인정해주는 등 가치 판단적인 평가를 해주는 지원을 의미한다. 점수가 높을수록 높은 사회적 지지를 받고 있다고 지각하는 것으로 해석할 수 있다. 각 문항은 Likert 5점 척도로 평정하게 되어 있으며, 점수가 높을수록 보육교사가 동료교사로부터 높은 사회적 지지를 받고 있다고 지각하는 것으로 해석할 수 있다. 연구도구의 신뢰도계수는 Cronbach $\alpha=.96$ (정서적 지지 .87, 정보적 지지 .89, 도구적 지지 .86 , 평가적 지지 .88 )이다.

\subsection{3 보육교사의 조직몰입}

보육교사의 조직몰입을 측정하기 위해 Allen과 Meyer(1991)[28], 마상진(2004)[29], 연구에서 제시된 설문지를 학교 조직에 맞게 국승오(2009)[30]가 재구성한 것을 정미영(2010)[19]이 보육 기관에 적합하도록 수정한 설문지를 사용하였다. 본 도구는 정서적 몰입(8문항), 지속적 몰입(8문항), 규범적 몰입(7문항)의 3 가지 하위요인에 걸쳐 총 23 문항으로 구성되어 있다. 하위요인별 내용을 살펴보면 '정서적 몰입'은 자신이 스스로 원해서 몰입하는 행동으로, 조직에 대해 지속해서 느끼는 심리적 애착이라 할 수 있다. ‘지속적 몰입’은 조직을 떠남으로써 발생하는 경제적, 사회적 비용이 크므로 지속해서 조직의 구성원으로 남으려는 심리적인 상태를 의미한다. ‘규범적 몰입’은 자신이 속한 조직에서 자신의 역할을 수행해야 한다는 책임감과 조직에 남아 있어야 한다고 느끼는 도덕적 의무감을 의미한다. 각 문항은 Likert 5 점 척도로 평정하게 되어 있으며, 점수가 높을수록 보육교사의 조직몰입 정도가 높음을 의미한다. 연구도구의 신뢰도계수는 Cronbach $\alpha=.77$ (정서적 몰입 .84, 지속적 몰입 .81, 규범적 몰입 .79)이다.

\section{3 연구절차}

설문내용의 타당성을 확인하기 위해 2019년 12월 26일에서 12월 30일까지 본 연구의 연구대상에 포함되지 않는 보육교사 10 명을 대상으로 예비조사를 수행하였다. 설문지 문항에 문제점이 발견되지 않음을 확인한 후, 2020년 1월 1일부터 1월 31 일까지 G 도와 I 시에 소재한 보육 기관 중 연구 참여 의사를 밝힌 기관에서 본 연구자가 직접 방문하여 설문지를 배포하거나, 우편으로 발송하였다. 총 270부를 배부하였고, 누락 및 불성실한 답변을 한 설문지는 제외한 최종 240부를 통계 분석에 사용하였다.

\section{4 자료분석}

본 연구에 수집된 자료는 SPSS 22.0 프로그램을 사용하여 분석하였다. 연구대상의 일반배경 특성을 파악하기 위하여 빈도 및 백분율을 구하고 척도의 신뢰도 및 타당도를 검토하기 위하여 Cronbach's $\alpha$ 계수를 산출하였다. 원장의 서번트 리더십과 동료교사의 사회적 지지 그리고 보육교사의 조직몰입 간의 상관관계를 알아보기 위해 Pearson의 
The Effect of Director's Servant Leadership and Social Support of Colleague Teachers on Childcare Teachers' Organizational Commitment

상관관계 분석을 시행하였고, 원장의 서번트 리더십과 동료교사의 사회적 지지가 보육교사의 조직몰입에 미치는 상대적 영향력을 알아보기 위해 다중 회귀분석을 실시하였다.

\section{3. 연구결과}

\section{1 원장의 서번트 리더십, 동료교사의 사회적 지지, 보육교사의 조직몰입 간의 관계}

원장의 서번트 리더십과 동료교사의 사회적 지지와 보육교사의 조직몰입 간의 관계를 알아보기 위해 상관관계 분석(Pearson's Correlation Analysis)을 실시하였으며, 그 결과는 아래의 [표 1]과 같다. 원장의 서번트 리더십(전체)과 보육교사의 조직몰입(전체) 간에 $\mathrm{r}=.62(\mathrm{p}<.01)$ 의 정 $(+)$ 적 상관관계가 나타났으며, 이는 원장의 서번트 리더십이 높을수록 보육교사의 조직몰입이 높은 것을 의미한다. 이어서 동료교사의 사회적 지지(전체)와 보육교사의 조직몰입(전체) 간에도 $\mathrm{r}=.53(\mathrm{p}<.01)$ 의 정 $(+)$ 적 상관관계가 나타났으며, 이는 동료교사의 사회적 지지가 높을수록 보육교사의 조직몰입이 높음을 의미한다. 끝으로 원장의 서번트 리더십(전체)과 동료교사의 사회적 지지(전체) 간에 $\mathrm{r}=.59(\mathrm{p}<.01)$ 의 정 $(+)$ 적 상관관계가 나타났고, 이는 원장의 서번트 리더십이 높을수록 동료교사의 사회적 지지가 높음을 의미한다.

[표 1] 연구변인 간 상관관계

[Table 1] Correlation among Research Variables

\begin{tabular}{|c|c|c|c|c|c|c|c|c|c|c|c|c|c|c|c|c|c|}
\hline & 변인 & 1 & 2 & 3 & 4 & 5 & 6 & 7 & 8 & 9 & 10 & 11 & 12 & 13 & 14 & 15 & 16 \\
\hline & 1.가치존중 & 1 & & & & & & & & & & & & & & & \\
\hline & 2. 성장지원 & $.83 * *$ & 1 & & & & & & & & & & & & & & \\
\hline & 3. 공동체지원 & $.84 * *$ & $.84 * *$ & 1 & & & & & & & & & & & & & \\
\hline 서번트 & 4.진정성 & $.81^{* *}$ & $.77 * *$ & $.81^{* *}$ & 1 & & & & & & & & & & & & \\
\hline & 5.리더십발휘 & $.83^{* *}$ & $.83^{* *}$ & $.81^{* *}$ & $.83^{* *}$ & 1 & & & & & & & & & & & \\
\hline & 6.리더십공유 & $.81^{* *}$ & $.84^{* *}$ & $.83^{* *}$ & $.82 * *$ & $.88^{* *}$ & 1 & & & & & & & & & & \\
\hline & 7.전체 & $.93 * *$ & $.93 * *$ & $.92 * *$ & $.91 * *$ & $.94 * *$ & $.93 * *$ & 1 & & & & & & & & & \\
\hline & 8.정서적지지 & $.55^{* *}$ & $.44 * *$ & $.51^{* *}$ & $.52 * *$ & $.51^{* *}$ & $.53^{* *}$ & $.55^{* *}$ & 1 & & & & & & & & \\
\hline & 9.정보적지지 & $.55^{* *}$ & $.48^{* *}$ & $.52^{* *}$ & $.53 * *$ & $.52^{* *}$ & $.53^{* *}$ & $.56^{* *}$ & $.85^{* *}$ & 1 & & & & & & & \\
\hline $\begin{array}{l}\text { 동됴기사 } \\
\text { 사회적 }\end{array}$ & 10.도구적지지 & $.55^{* *}$ & $.46^{* *}$ & $.49^{* *}$ & $.52 * *$ & $.50^{* *}$ & $.51^{* *}$ & $.55^{* *}$ & $.87 * *$ & $.83^{* *}$ & 1 & & & & & & \\
\hline 지지 & 11.평가적지지 & $.56^{* *}$ & $.49^{* *}$ & $.51^{* *}$ & $.53^{* *}$ & $.53^{* *}$ & $.54 * *$ & $.51^{* *}$ & $.86^{* *}$ & $.88^{* *}$ & $.87 * *$ & 1 & & & & & \\
\hline & 12.전체 & $.58 * *$ & $.49 * *$ & $.54^{* *}$ & $.55 * *$ & $.55^{* *}$ & $.56^{* *}$ & $.59^{* *}$ & $.95^{* *}$ & $.94 * *$ & $.94 * *$ & $.96^{* *}$ & 1 & & & & \\
\hline & 13. 정서적몰입 & $.66^{* *}$ & $.64 * *$ & $.63^{* *}$ & $.64 * *$ & $.64 * *$ & $.66^{* *}$ & $.70^{* *}$ & $.62 * *$ & $.64 * *$ & $.64 * *$ & $.66^{* *}$ & $.67 * *$ & 1 & & & \\
\hline 보육교사 & 14.지속적몰입 & $.32 * *$ & $.35^{* *}$ & $.35^{* *}$ & $.32 * *$ & $.34^{* *}$ & $.39 * *$ & $.37^{* *}$ & $.32 * *$ & $.35^{* *}$ & $.32 * *$ & $.33^{* *}$ & $.35^{* *}$ & $.50 * *$ & 1 & & \\
\hline 조직몰입 & 15.규범적몰입 & $.44 * *$ & $.44 * *$ & $.51^{* *}$ & $.49 * *$ & $.43^{* *}$ & $.43^{* *}$ & $.50^{* *}$ & $.47 * *$ & $.28 * *$ & $.29 * *$ & $.29 * *$ & $.31 * *$ & $31 * *$ & $.50 * *$ & $.58 * *$ & \\
\hline & 16.전체 & $.57 * *$ & $.59 * *$ & $.59^{* *}$ & $.55^{* *}$ & $.56^{* *}$ & $.60 * *$ & $.62^{* *}$ & $.49 * *$ & $.51 * *$ & $.50 * *$ & $.52 * *$ & $.53 * *$ & $80 * *$ & $.86^{* *}$ & $.82 * *$ & 1 \\
\hline
\end{tabular}

$* * \mathrm{p}<.01$

\section{2 원장의 서번트 리더십과 동료교사의 사회적 지지가 보육교사의 조직몰입에 미치는 영향}

원장의 서번트 리더십과 동료교사의 사회적 지지가 보육교사의 조직몰입에 통계적으로 유의미한 영향을 미치며 $(\mathrm{F}=89.87, \mathrm{p}<.001)$, 보육교사의 조직몰입에 $43 \%$ 를 설명하는 것으로 
나타났다. 이어서 원장의 서번트 리더십과 동료교사의 사회적 지지에 대한 유의성을 판단하기 위해 $\mathrm{t}$ 값의 유의도를 살펴본 결과, 원장의 서번트 리더십과 동료교사의 사회적 지지가 유의한 것으로 나타났다. 독립변인별로 보육교사의 조직몰입에 미치는 상대적 영향력을 파악하기 위해 표준화된 계수 $(\beta)$ 를 살펴본 결과, 원장의 서번트 리더십의 $\beta$ 값이 $0.47(\mathrm{p}<.001)$, 동료교사의 사회적 지지 $\beta$ 값이 $0.25(\mathrm{p}<.001)$ 로 원장의 서번트 리더십과 동료교사의 사회적 지지가 높아지면 보육교사의 조직몰입도 높아질 것으로 예측할 수 있으며, 보육교사의 조직몰입에 미치는 상대적 영향력 순위는 원장의 서번트 리더십, 동료교사의 사회적 지지 순으로 나타났다.

[표 2] 다중회귀분석

[Table 2] Multiple Regression Analysis

\begin{tabular}{|c|c|c|c|c|c|c|}
\hline \multirow{2}{*}{ 독립변인 } & \multicolumn{7}{|c|}{ 보육교사의 조직몰입 } \\
\cline { 2 - 7 } & $\mathrm{B}$ & $\mathrm{SE}$ & $\beta$ & $\mathrm{t}$ & $\mathrm{F}$ & $R^{2}$ \\
\hline 원장의 서번트 리더십 & .35 & .05 & .47 & $7.83^{* * *}$ & \multirow{2}{*}{$89.87^{* * *}$} & \multirow{2}{*}{.43} \\
\hline 동료교사의 사회적 지지 & .24 & .06 & .25 & $4.19^{* * *}$ & & \\
\hline \multirow{2}{****}{$p<.001$} & \multicolumn{7}{|c|}{}
\end{tabular}

\section{4. 논의 및 결론}

본 연구는 양질의 보육을 제공하기 위하여 보육교사의 조직몰입에 영향을 미치는 요인들을 파악하기 위해 이루어졌으며, 본 연구를 통해 얻은 결과를 요약하고 논의하면 다음과 같다.

연구문제 1 에서 원장의 서번트 리서십과 동료교사의 사회적 지지, 보육교사의 조직몰입 간의 관계는 모두 유의미한 정 $(+)$ 적 상관관계가 있는 것으로 나타났다. 본 연구에서의 원장의 서번트 리더십이 높을수록 보육교사의 조직몰입이 높았다는 연구결과는 정미영(2009)[19], 홍경진(2010)[31], 고현(2015)[32]의 연구를 지지한다. 또한 조직의 리더가 명령과 지시하는 기존의 전통적인 리더십보다 구성원들의 자발적인 헌신과 참여를 끌어내고, 책임감과 주인의식을 고취하는 서번트 리더십을 가질 때 구성원들이 조직몰입을 얻는다고 보고한 김용학(2010)[33]의 연구결과와도 일치한다. 이와 같은 연구결과는 보육에서 중요한 역할을 수행하는 보육교사의 조직에 대한 몰입을 높이기 위해 원장이 서번트 리더십을 발휘하는 것이 중요함을 시사한다.

동료교사의 사회적 지지가 높을수록 보육교사의 조직몰입이 높다는 연구결과는 유화(2017)[34], 황혜림(2019)[35]의 연구결과와 일치하고, 초임 보육교사의 직장 내 사회적 지지와 조직몰입 간 유의미한 정적 상관관계를 보고한 강신영, 문혁준(2019)[36]의 연구결과와 일치한다. 또한, 유아교사의 직장 내 사회적 지지를 높게 인식할수록 조직몰입에 긍정적인 효과를 미친다고 보고한 문태형(2021)[37]의 연구결과와도 같다. 이와 같은 연구결과는 보육교사가 직장에서 동료로부터 받는 신임, 사랑, 존중과 같은 사회적 지지가 높을수록 조직에 대해 더 강한 몰입을 하는 것으로 해석할 수 있다.

연구문제 2에서는 원장의 서번트 리더십과 동료교사의 사회적 지지가 보육교사의 조직몰입에 미치는 영향력을 $43 \%$ 설명하였으며, 상대적 영향력의 경우 원장의 서번트 리더십이 동료교사의 사회적 지지보다 영향력이 높은 것으로 나타났다. 본 연구의 결과는 원장의 서번트 리더십이 보육교사의 조직몰입에 유의미한 영향을 미친다는 
정미영(2010)[19], 예남희, 민하영(2014)[38]의 연구결과와 일치하고, 사회적 지지가 조직몰입에도 영향을 미친다는 김경의, 정영실, 이선경(2014)[39], 이영미(2013)[22] 결과와 맥을 같이 한다.

연구 결과를 토대로 보육 현장에서 원장은 서번트 리더십을 적절하게 발휘하여 기관 내 보육교사에게 교육의 목표 및 계획을 분명하게 제시하고, 중요한 의사결정 권한을 보육교사와 공유하며 보육교사의 요구에 민감하게 대처하고 그들을 보육전문가로서 성장할 수 있도록 지원하는 자세가 요구됨을 알 수 있다. 또한 원장은 보육교사들과 원활한 의사소통을 하며 영향력을 행사할 수 있어야 하고, 상호존중과 조직이 잘 화합하는 분위기를 형성하면 보육교사의 조직몰입을 증진하게 시켜 결과적으로 보육의 질 향상에 기여할 수 있을 것이다. 그러므로 원장을 대상으로 서번트 리더십을 증진하기 위한 체계적인 연수 또는 교육 프로그램이 개발 및 지원되어야 할 것이며, 이때 기관의 규모, 유형 등 다양한 상황을 고려한 기관 맞춤형 프로그램형으로 제공되어야 할 것이다.

본 연구에서는 보육교사를 대상으로 이루어진 설문지 기법을 활용한 양적연구이므로 후속 연구에서는 교사 인터뷰 및 관찰법 같은 연구 방법을 통해 보육 현장에서의 깊이 있는 고찰 및 해석이 이루어질 필요가 있다고 사료된다.

\section{References}

[1] Y. M. Kwon, The Perception of the Speciality on the Child-care Teachers and the Relationship between Social Supporting and Job Satisfaction, Yeungnam University, Master's thesis, pp.1-73, (2014)

[2] D. Y. Ryu, A Study on the Relations between Kindergarten Teachers' Turnover Reasons and their Work Environment and Job Satisfaction, Hankuk University of Foreign Studies, Master's thesis, pp.1-52, (2011)

[3] J. A. Kim, Organizational Culture and Effectiveness of Child Care Centers Perceived by Child Care Practitioners, Duksung Women's University, Doctoral dissertation, pp.1-199, (2008)

[4] S. A. Park, The Relation among Organizational Commitment, Job Satisfaction and Intrinsic Motivation for Teaching Job of Daycare Teacher, Dongyang University, Master's thesis, pp.1-72, (2009)

[5] S. J. Cho, S. B. Moon, H. Y. Min, The Influence of the Self-Efficacy and the Social Support on the Organizational Commitment of Kindergarten and Child Care Teachers, Journal of Families and Better Life, (2008), Vol.26, No.2, pp. 25-32, UCI: G704-000320.2008.26.2.007

[6] J. E. Park, Influence of Self-Leadership on Teaching Efficacy and Organizational Commitment in Childcare eachers: with Mediating Effects of Job Satisfaction, Seoul Hanyoung University, Doctoral dissertation, pp.1-164, (2015)

[7] H. W. Lee, S. J. Lim, The Effects of Early Childhood Teacher's Motivational Self Concept and Emotional Intelligence on Organizational Commitment, Theory and Practice of Education, (2011), Vol.16, No.3, pp.111-131, UCI : G704001913.2011.16.3.001

[8] J. H. Kwon, P. H. Kim, Structural Relationships among Directors' Emotional Leadership, Teacher Efficacy, Job Satisfaction and Organizational Commitment as Perceived by Early Childhood Teachers, The Korean Journal Child Education, (2015), Vol.24, No.1. pp.81-98, UCI : G704-001652.2015.24.1.004

[9] S. H. Lee, The effect of early childhood teachers' empowerment on teacher efficacy and organizational commitment, Soongsil University, Master's thesis, pp.1-60, (2018)

[10] S. R. Jung, K. N. Lee, The Effects of Directors' Coaching Leadership, Child Care Center Teachers' Job Stress and Empowerment on Teachers' Organizational Commitment, The Journal of Korea Open Association for Early Childhood Education, (2016), Vol.21, No.4, pp.225-249, UCI: G704-000666.2016.21.4.019

[11] Y. H. Cho, The Study about the Moderating Effects of Institution Type in the Relationship between Organization 
Culture and Commitment to Organization, Sookmyung Women's University, Master's thesis, pp.1-90, (2016)

[12] J. H. Ma, A Study on the Relationship between Child Care Center Director's Servant Leadership and Teacher's Empowerment and Teaching Professionalism, Duksung Women's University, Master's thesis, pp.1-79, (2015)

[13] M. R. Park, The Influence of the Director's Servant Leadership Perceived by Childcare Teacher on Instructional Creativity : The Meditating Effect of Teacher's Empowerment, Dong-A University, Master's thesis, pp.1-61, (2020)

[14] J. E. Park, The Effect of Director's Servant Leadership on Teacher Efficacy and Organizational Commitment, Chongshin University, Master's thesis, pp.1-77, (2018)

[15] J. S. Jung, The Mediating Effect of Teacher Happiness on the Relationship between Child-care Teacher-Perceived Head Person's Servant Leadership and Organizational Commitment, Chungang University, Master's thesis, pp.1-77, (2019)

[16] N. S. Go, A Study on the Structural Effect of the Principal's Servant Leadership on the School Organization Through Teachers' Commitment in Korean Elementary Schools, Konkuk University, Doctoral dissertation, pp.1-136, (2013)

[17] M. H. Lee, An Effect of the Kindergarten Principal's Leadership Style on Teachers' Organizational Commitment and Job Satisfaction, Theory and Practice of Education, (2009), Vol.14, No.2, pp.55-78, UCI: G704-001913.2009.14.2.008

[18] G. N. Gwon, H. Y. Min, The Relationships among Principal's Transformational and Transactional Leadership, Subjective Quality of Life of Teacher, and Organizational Commitment of Teacher in Kindergarten and Day Care Center, Korean Journal of Human Ecology, (2009), Vol,18, No.4, pp.857-867, UCI: G704-001335.2009.18.4.010

[19] M. Y. Jeong, The Effects of Childcare Teacher' Perception of Their Director's Servant Leadership on Director Trust and Organizational Commitment, Kookmin University, Master's thesis, pp.1-61, (2010)

[20] S. H. Jeong, The Influence of Teacher Efficacy and Social Support on the Burnout of Infant Nursing Teachers, Pukyoung National University, Master's thesis, pp.1-85, (2013)

[21] S. K, Lee, Teachers' Interaction to Young Children, Play Flow and Self-efficacy of Young Children according to Early Childhood Teachers' Teaching Flow, Wonkwang University, Doctoral dissertation, pp.1-115, (2015)

[22] Y. M. Lee, The Structure relationship of Social Support, Emotional Labor, Daegu Catholic University, Doctoral dissertation, pp.1-145, (2013)

[23] A. J. Laub, Assessing the Servant Organization: Development of the Servant Organizational Leadership Assessment(SOLA) Instrument, Florida Atlantic University, Doctoral dissertation, pp.1-128, (1999)

[24] L. C. Spears, Reflections on Leadership: How Robert K. Greenleaf's Theory of Servant-Leadership Influenced Today's Top Management Thinkers, John Wiley \& Sons, pp.1-14, (1995)

[25] B. R. Sung, The Effects of Servant Leadership of School Principals on the Level of Teachers' Psychological Empowerment and Job Satisfaction, Cheongju University, Doctoral dissertation, pp.1-127, (2010)

[26] J. W. Park, A Study to Development a Scale of Social Support, Yonsei University, Doctoral dissertation, pp.1-127, (1985)

[27] H. J. Ahn, The Relation of Emotional Labor of Kindergarten Teachers with Job Satisfaction and Social Support, Ewha Womans University, Master's thesis, pp.1-90, (2013)

[28] N. J. Allen, J. P. Meyer, The Measurement and Antecedents of Affective Continuance and Normative Commitment to the Organization, Journal of Occupational Psychology, (1991), Vol.63, No.1, pp.1-18, DOI: 10.1111/j.20448325.1990.tb00506.x

[29] S. J. Ma, The Relationship between Value Orientations towards Vocational Education and Orginizational Commitment of Vocational High School Teachers, Seoul National University, Doctoral dissertation, pp.1-208, (2004)

[30] S. O. Kook, The Effect of Transformational Leadership and Servant Leadership of School Principal on Teachers' Efficacy and Organizational Commitment, Kongju National University, Doctoral dissertation, pp.1-138, (2009)

[31] G. J. Hong, The Effects of Childcare Teacher' perception of Their Director's Transformational Leadership on the Selfefficacy and Organizational Commitment, Kookmin University, Master's thesis, pp.1-58, (2010) 
[32] H. Go, The Influence of Director's Servant Leadership on Relation to Empowerment and Organizational Commitment of Childcare Teachers, Korean Journal of Early Childhood Education Research, (2015), Vol.35, No.1, pp.5-28, DOI: $10.18023 / \mathrm{kjece} .2015 .35 .1 .001$

[33] Y. H. Kim, Servant Leadership and Organizational Commitment : the Roles of Empowerment and Trust in Leader, Yeungnam University, Doctoral dissertation, pp.1-169, (2010)

[34] H. Yu, The Effect of Social Support for Child-care Teachers on Organizational Commitment and Teaching Efficacy, Choongang University, Master's thesis, pp.1-75, (2017)

[35] H. R. Hwang, Influence of Social Support and Organizational Commitment on Teacher Professionalism in Childcare Teachers, Chongshin University, Master's thesis, pp.1-70, (2019)

[36] S. Y. Kang, H. J. Moon, The Effects of Beginning Teachers' Teaching Efficacy and Social Support on Organizational Commitment, The Korea Association of Child Care and Education, (2019), No.118, pp.1-24, DOI: $10.37918 /$ kce.2019.09.118.1

[37] T. H. Moon, The Influence of Early Childhood Teachers' Motivation for Choosing the Teaching Profession and Social Support on Organizational Commitment, Early Childhood Education Research \& Review, (2021), Vol.25, No.4, pp.526, DOI: 10.32349/ECERR.2021.8.25.4.5

[38] N. H. Ye, H. Y. Min, The Structural Relationship between Director's Servant Leadership, Teacher's Empowerment and Organizational Cynicism Affecting on Teacher's Organizational Commitment at Kindergartens and Child Care Centers, Korean Journal of Child Studies, (2014), Vol.35, No.3, pp.119-135, DOI: 10.5723/KJCS.2014.35.3.119

[39] K. E. Kim, Y. S. Jung, S. K. Lee, The Relationship Between Early Childhood Teachers' Social Support, Job Satisfaction, and Organizational Commitment, Journal of Children's Literature and Education, (2014), Vol.15, No.3, pp.323-341, UCI: G704-001817.2014.15.3.012 